\title{
Abnormal Flexure
}

National Cancer Institute

\section{Source}

National Cancer Institute. Abnormal Flexure. NCI Thesaurus. Code C124487.

A flexure that is deviating from the norm or outwith the bounds of what is considered normal. 